\title{
A HONRA NA RELAÇÃO ENTRE DETENTOS CRENTES E NÂO-CRENTES
}

\author{
Alessandro Bicca \\ Universidade Federal do Rio Grande do Sul
}

Resumo: O presente artigo é um recorte de uma pesquisa mais ampla que teve como tema a utilização do discurso religioso na legitimação de atos de violência. Para tal, pesquisei, entre os anos de 2003 e 2004, um grupo evangélico pentecostal constituído integralmente por detentos do sistema prisional gaúcho. Constatei que o conceito de honra entre os detentos assume características singulares que norteiam, de forma geral, todas as relações que estabelecem no universo carcerário. Circunscrevo a discussão que segue na análise do significado e da aquisição da honra na relação entre detentos crentes e não-crentes.

Palavras-chave: conversão religiosa, crime, honra, sistema prisional.

Keywords: crime, honor, prison system, religion conversion.

No Rio Grande do Sul atualmente existem 90 presídios. Dentre estes a Penitenciária Estadual do Jacuí (PEJ), localizada no município de Charqueadas, apresenta-se como o maior presídio para presos condenados do estado. Na PEJ 1650 homens dividem um espaço projetado para abrigar 600 detentos. $^{1}$

Nesse estabelecimento prisional podemos encontrar um universo profícuo em expressóes religiosas. ${ }^{2}$ As igrejas evangélicas pentecostais são as que

${ }^{1}$ Os números apresentados ao longo deste artigo foram fornecidos pela Susepe/RS, e são referentes a novembro de 2004.

$2 \mathrm{Na}$ época da pesquisa encontrei em atividade na PEJ grupos católicos, da Igreja Universal do Reino de Deus, Assembléia de Deus, Igreja Pentecostal Deus é Amor, Igreja Internacional da Graça de Deus, da umbanda, espírita kardecista, além de um grupo criado por presos, no próprio presídio, que cultuam "entidades” reveladas apenas aos seus iniciados. 
mais se impõem, tanto pela presença do trabalho realizado pela comunidade que está fora do presídio como pelo número de adeptos entre os detentos.

O Estrela do Cárcere, grupo religioso vinculado à Igreja Assembléia de Deus e constituído exclusivamente por detentos, se destaca entre os demais por ter o maior e mais bem organizado grupo de fiéis. Fundado em 1991, por quatro presos, hoje conta com 145 integrantes, quase o dobro de todas as outras manifestações religiosas juntas.

Um outro diferencial do Estrela do Cárcere em relação às demais denominações religiosas é o fato deste ser o único grupo que reside em uma galeria exclusiva aos seus integrantes. Desde o ano de 2000 convivem em um local, sem divisões ou celas - antigo teatro desativado nos anos 1990 para abrigar detentos devido à superlotação carcerária -, que serve de dormitório, refeitório, sala de estudos, espaço de convivência para receberem visitas e realizarem cultos.

Entre os anos de 2003 e 2004 desenvolvi com esse grupo uma pesquisa etnográfica que tinha como objetivo analisar a utilização do discurso religioso na legitimação de atos de violência. ${ }^{3}$ Apresento, a seguir, um breve recorte dessa pesquisa, onde abordo a constituição da honra na relação específica entre detentos não-crentes e os integrantes do Estrela do Cárcere. Na discussão que segue utilizo como chave de leitura o conceito de honra definido por Pitt-Rivers (1968, p. 22, tradução minha), como sendo um "[...] nexo entre ideais de uma sociedade e a reprodução desses mesmos ideais no indivíduo, pela aspiração deste de personificá-la”.

\section{ENTRE O FORMAL E O CONSENSUAL}

Desde Foucault (2004) e Goffman (2003), afirmar que o sistema prisional funciona como uma microssociedade que apresenta regras próprias tornou-se ao mesmo tempo lugar comum e premissa indispensável a quem

3 Dissertação de mestrado apresentada no Programa de Pós-Graduação em Antropologia Social da Universidade Federal do Rio Grande do Sul. 
se propõe estudar essas instituições. Posto isso, para compreendermos o significado de honra na relação entre os detentos crentes e não-crentes precisamos nos situar no ambiente em que estes homens vivem, e conhecermos minimamente os seus códigos.

Quando um detento ingressa na PEJ lhe é passado, pelos funcionários encarregados da segurança, um conjunto de normas acerca da conduta, horários, enfim, o que ele pode ou não fazer dentro do presídio. Entretanto, como pude perceber, estas "recomendações" funcionam na relação do preso com os funcionários do presídio e antes dele entrar para a galeria. Uma vez dentro das galerias, os presos estabelecem outras formas de relacionamento, regras e hierarquias.

Os funcionários da PEJ, por mais que percebam esse reordenamento das regras, não interferem diretamente nessa dinâmica, deixando que os próprios presos procurem o equilíbrio nas suas relações. Esta "liberdade" dos detentos de gerenciarem as suas próprias relações é tolerada pela direção do presídio, desde que não ameace a segurança e não cause transtornos à rotina diária de trabalho.

Portanto, os presos transitam entre dois códigos, que regulam seu comportamento: um formal, imposto pela direção do presídio, e outro implícito e consensual, consequiência das relações estabelecidas entre os presos.

Os limites da ação tanto de funcionários quanto de presos fica assim circunscrito espacial e temporalmente. Dentro das galerias os presos ditam as regras - definem quem dormirá em camas ou no chão, quem trabalhará e em qual setor, quem pode ou não pode residir em determinada cela ou galeria e quais puniçóes serão aplicadas a quem desrespeitar as suas normas -, fora desse espaço são os guardas que determinam as regras a serem seguidas. Temporalmente, onde durante o dia ocorre o domínio da "lei do Estado", à noite, quando o número de funcionários e o volume das atividades rotineiras diminui, temos o domínio da "lei dos presos".

Para organizar as relações entre os detentos e ser mediador com a direção do presídio, existe em cada galeria um preso que desempenha a função de "plantão" ou "prefeito", que conta com auxiliares para garantir a sua segurança e o cumprimento das suas ordens. Os "plantões” são escolhidos pelos pró- 
prios detentos e geralmente são pessoas vinculadas a algum grupo criminoso e que obtiveram "sucesso na vida do crime" conseguindo, assim, adquirir capital simbólico ${ }^{4}$ que lhes confere status e poder nos presídios. Entretanto, o "plantão" nem sempre é o líder da galeria. Em alguns casos, este é apenas um representante dos reais líderes. Contudo, mesmo não sendo o principal na cadeia de comando, ele tem status e pode, na ausência do verdadeiro líder por ter sido transferido de presídio, por estar em cela separada cumprindo alguma punição administrativa, dentre outros -, exercer a liderança. Outro aspecto é que o "plantão" não necessariamente precisa integrar um grupo criminoso fora dos presídios, mas para exercer a liderança em uma galeria precisa, quando ingressa no sistema prisional, vincular-se a uma facção criminosa.

\section{O SUCESSO NA VIDA DO CRIME}

Entre os detentos da PEJ encontramos uma classificação que atribui uma escala de valores aos diversos tipos de crimes. Essa escala, no entanto, não é determinista e hermética, pois obedece a um conjunto de variáveis objetivas e subjetivas que torna impraticável entendê-la linearmente. ${ }^{5}$ Grosso modo, os crimes que alcançam maior respeito entre os detentos são o assalto a banco e o seqüestro. Esse respeito advém principalmente de três fatores: por renderem lucro financeiro, pela dificuldade e periculosidade de execução, bem como por exigirem um grau de sofisticação no seu planejamento. No extremo oposto estão os crimes sexuais - que também têm uma graduação entre si -, onde seus autores estão alijados de uma relação horizontal com os demais e destituídos de qualquer possibilidade de ascensão hierárquica.

O tipo de crime cometido - e suas múltiplas combinações possíveis - é um dos aspectos que conferem ao seu autor o reconhecimento no universo

${ }^{4}$ Sobre capital simbólico, conferir Bourdieu (2002).

5 A hierarquia não é uma sucessão de ordens superpostas e rígidas, mas se constitui dentro de um contexto que, se alterado, a posição hierárquica ocupada também se altera. Sobre hierarquia, conferir Dumont (1997). 
criminoso como alguém que obteve "sucesso na vida do crime". Além do crime este reconhecimento sofre influência das relações de amizade que estabelece, da visibilidade que o delito recebe na sociedade e a repercussão obtida entre os criminosos. A forma como essa pessoa foi presa e a conduta dela dentro do presídio também contribuem para a constituição do status pessoal. Aqueles que ao serem presos não delatam seus companheiros, não fazem acordos com a polícia, resistem à prisão e, mais ainda, provocam o ferimento ou mesmo a morte de policiais, são respeitados. Outra maneira de manter, ampliar ou construir seu status é mostrar-se impiedoso dentro do próprio presídio.

Nesse ambiente agressivo, onde a violência e o mais forte ${ }^{6}$ detêm o poder, a honra é a unidade fundamental das relaçôes. ${ }^{7}$ Sem honra todo o status adquirido pelo preso com o delito que cometeu ou com as relaçóes do universo criminoso que estabeleceu de nada vale.

Os que burlam o código de honra são severamente punidos e, dependendo do caso, desrespeitá-lo significa uma sentença de morte. A honra para eles está em não trair os "códigos da cadeia”, que implica ter hombridade revidar as agressóes sofridas -, manter a palavra até as últimas consequiências, não delatar os demais presos, resolver todas as questôes entre os próprios detentos e respeitar os que ocupam posição hierárquica superior dentro do grupo que integra.

O Estrela do Cárcere, embora professe o abandono completo da prática de crimes e aceite todos aqueles que desejam conhecer a "Palavra de Deus" sem distinção do delito cometido, quando estabelecem relações com os detentos não-crentes estão sujeitos ao mesmo código usado por estes para conferir honra e localizar-se hierarquicamente.

${ }^{6}$ Força, aqui, não necessariamente ligada ao aspecto físico. A força está associada também ao tipo de relação que essa pessoa estabelece no "mundo" do crime, assim como com a capacidade individual de manipular os demais detentos.

7 Conforme Peristiany (1968), a honra torna-se mais significativa em sociedades fechadas, excluídas, onde as relaçôes diretas entre os indivíduos predominam ou a personalidade social assume importância relevante. 


\section{EU TAMBÉM PRATIQUEI CRIMES}

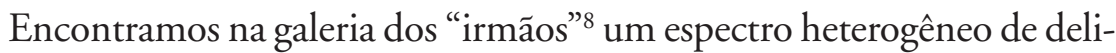
tos, pois para ingressar no Estrela do Cárcere o "novo crente" precisa somente demonstrar, através do seu comportamento, que deseja aceitar a "Palavra de Deus”. Esta não restrição do acesso ao grupo a nenhum tipo de crime, o fato de conviverem todos juntos em uma mesma galeria e receberem auxílio roupas, comidas e material de higiene - da comunidade evangélica de fora do presídio, aliado à presença de alguns “irmãos” que, após se converterem no presídio e saírem em liberdade, retornaram ao sistema prisional por incorrerem em novos delitos, são alguns dos fatores que contribuem para o discurso proferido quase que mecanicamente entre funcionários e detentos não-crentes, de que os "irmãos" só afirmam que se converteram para "escapar" da realidade violenta e insalubre do presídio.

Outro aspecto que contribui para a desconfiança da real conversão dos "irmãos" é que estes, ao mesmo tempo em que procuram personificar os ideais e valores cristãos, também transitam pelo código de honra do universo carcerário. Paradoxalmente, é a manutenção e a persistência em um comportamento que obedece tanto aos preceitos da igreja quanto aos dos demais presos que atesta a verdadeira conversão. Diariamente, os crentes têm de provar que se converteram não somente com "boas obras" e "testemunho da Palavra de Deus", mas também obedecendo ao código de honra dos presos não-crentes.

Sendo assim, por mais que ao se converter os “irmãos" procurem ressignificar a sua história de vida, preguem o abandonando da prática de crimes e adotem o discurso pentecostal de ética puritana, na relação com os detentos não-crentes passam a utilizar justamente o status adquirido com o delito que cometeram para acessarem e evangelizarem os demais presos.

8 "Irmãos" ou crentes é como os evangélicos pentecostais se identificam e são identificados pelos funcionários e demais detentos. No entanto, aqui me refiro especificamente aos integrantes do Estrela do Cárcere. 
O líder do Estrela do Cárcere personifica essa dualidade. Mesmo afirmando que desde a sua conversão é "um novo homem", lança mão de crimes que constam em sua biografia - assaltos a banco, homicídios, latrocínios, tráfico de drogas, seqüestros, assim como inúmeras fugas do sistema penitenciário, que lhe valeram uma condenação de 300 anos de detenção - para adquirir status junto ao universo carcerário. No entanto, afirma que no início não foi fácil:

No início foi difícil porque o pessoal não acreditou muito na minha conversão. Eu era um líder aqui e estava sempre envolvido em uma tentativa de fuga, em algum tipo de bateção. Agitava muito e depois de convertido eu não fiz mais nada. $\mathrm{O}$ pessoal achou que eu estava me acovardando, que iria entregar todo mundo, dizer para a polícia tudo o que eu sabia. Podia ser morto a qualquer momento. Só que Deus é forte, eu perseverei e eles perceberam que a minha conversão era verdadeira.

Ao "persistir na fé" e, ao mesmo tempo, respeitar o código de honra entre os presos, conseguiu construir e consolidar sua imagem de "homem de Deus" no universo carcerário. Inicialmente como um homem perigoso, brutal e líder criminoso e depois como alguém que, mesmo se afastando da prática de delitos, não entregou seus companheiros e não negociou favores com as autoridades do presídio. A seguinte fala de um dos plantôes de galeria, na qual os "irmãos" têm um grupo de "missionários", ilustra o prestígio do líder do Estrela do Cárcere entre os detentos:

O pastor ${ }^{9}$ é um cara conhecido no mundo do crime. Ele aprontou muito. O pessoal respeita, até porque ele não deixava nada barato e nem pode mesmo né! [...] Quando saiu, foi sozinho, limpo.

9 "Pastor" é como funcionários, detentos não-crentes e crentes referem-se ao líder do Estrela do Cárcere. 
O discurso de covardia e de que estão se escondendo atrás da Bíblia perde força à medida que o crente alia sua história de crimes, obediência ao código de honra dos presos e conduta que respeite os preceitos da igreja. Apesar desse discurso esmorecer, a dúvida acerca da veracidade da conversão persiste, tanto entre detentos não-crentes como entre os funcionários. No entanto, para os detentos não-crentes não é a certeza da conversão - pois essa, como afirmam, somente é possível de ser avaliada quando o "irmão" sair em liberdade -, mas a conduta e o ser percebido como alguém honrado que garante aos crentes o acesso aos demais presos.

\section{MISSIONÁRIOS DE DEUS}

Para os “irmãos" a evangelização dos demais detentos constitui-se como a sua principal missão dentro do presídio. Com o intuito de propagar a "Palavra de Deus", organizam grupos de "missionários" que passam a residir em outras galerias.

Na organização dessas "missões" alguns passos são rigidamente seguidos. Primeiramente, é sempre o "plantão" quem procura o grupo religioso para que este envie alguns “irmãos” para a sua galeria. Essa negociação é feita diretamente entre os "plantões" e o líder do Estrela do Cárcere. A alegação dos "plantôes" para ter um grupo de "missionários” em sua galeria é que os "irmãos" são "calmos" e ajudam a manter a galeria "tranqüila". Essa justificativa, como pude perceber, é mais uma mensagem do "plantão" à direção do presídio de que a galeria está sob seu controle do que expectativa na ação dos "irmãos".

Para ter um grupo de “irmãos" em sua galeria, o "plantão" precisa garantir a segurança física - que não sejam agredidos por desafetos ou envolvidos em disputas internas pelo poder - e disponibilizar uma cela exclusiva aos crentes. O número de "irmãos missionários" oscila entre quatro e 20 por galeria, dependendo do espaço disponível na cela em que irão se alojar.

Cada grupo de "missionários" tem um líder, indicado pelo "pastor", que para ser escolhido precisa ter "bom testemunho cristão", ter cometido crimes que lhe confiram status e passar pelos critérios de honra dos detentos não- 
crentes. O mesmo rigor não se aplica aos demais integrantes, também escolhidos pelo "pastor", que não necessariamente precisam ter obtido "sucesso na vida do crime". As "missões" também servem para que esses "irmãos" possam constituir-se como "homens honrados" e demonstrarem a sua conversão e o "Poder de Deus em suas vidas" tanto para os detentos não-crentes como para os próprios integrantes do grupo evangélico.

A segurança desses "irmãos" é sobremodo valorizada, pois o único que pode autorizar qualquer tipo de punição a eles é o próprio "pastor" ${ }^{10}$ Todo e qualquer problema de relacionamento entre os "irmãos" e os demais detentos ${ }^{11}$ é comunicado imediatamente ao líder do grupo, que comunica ao "pastor". Identificado o problema, o "irmão" envolvido retorna à galeria do Estrela do Cárcere, podendo ou não ser substituído por outro. Independentemente de qualquer problema de relacionamento com um ou mais "irmãos" dentro da galeria, os demais não sofrem retaliações pelos detentos não-crentes.

Mesmo tendo a sua integridade física garantida, os "irmãos" estão sujeitos a provocações verbais. Não é incomum ouvirem piadas depreciativas, receberem propostas para a utilização de drogas, práticas sexuais, envolvimento em delitos, dentre outros. Essas provocaçóes, tanto para os crentes como para os não-crentes, são percebidas como um "teste" para os "irmãos", que ainda são observados com desconfiança pelos detentos.

Quando em "missão", os crentes passam a maior parte do tempo em suas celas orando, conversando entre si, fazendo grupos de estudo bíblicos e aulas de violão. Frente às rebeliôes, tentativas de fugas e ajustes de contas entre os detentos não-crentes, os "irmãos" não se envolvem e obedecem ao código de silêncio dos presos. Os crentes procuram, ao perceber a possibili-

\footnotetext{
${ }^{10}$ Desrespeitar esse acordo pode significar que o "plantão" não cumpre com a palavra empenhada, portanto não é um homem honrado e/ou não tem controle sobre o grupo que lidera, podendo inclusive perder a liderança para outro detento e até mesmo para outro grupo criminoso.

${ }^{11}$ Entre os problemas estão: o reconhecimento do "irmão" como sendo um ex-policial, um estuprador, por desentendimentos com outros criminosos antes da sua conversão, por aceitar participar de algum ato ilícito na galeria, dentre outros.
} 
dade de qualquer alteração na rotina da galeria, intervir com "conselhos" antes dos acontecimentos, porém quando estes são desencadeados não mais interferem.

É difícil, sabe, ouvir os gemidos e toda a confusão, mas se tentarmos fazer alguma coisa na hora não adianta nada. A gente tenta quando percebe que vai acontecer alguma coisa é falar com as pessoas antes, mas na hora fica todo mundo descontrolado e ninguém ouve nada. [...] a gente fica orando muito o tempo todo para que as coisas se resolvam bem. (Depoimento de um dos "irmãos" coordenadores dos grupos de missão).

Com a postura de "testemunho da Palavra de Deus", ao mesmo tempo em que respeitam o código de honra dos presos - com exceção de revidar a agressōes sofridas -, os missionários garantem a interlocução com a liderança da galeria e legitimam o discurso da conversão - mesmo que ainda sob suspeita - junto aos demais presos.

\section{FINALIZANDO}

Como demonstrei no decorrer deste artigo, entre os detentos, ser um crente - e como pude constatar, em linhas gerais, isso não está circunscrito apenas aos integrantes do Estrela do Cárcere, mas independe da denominação religiosa - não desmerece e tampouco garante o reconhecimento de alguém como uma pessoa honrada. Os "irmãos" - do mesmo modo aqueles vinculados a outros grupos religiosos - para serem respeitados têm que, além de cumprirem com as diretrizes da fé que professam, obedecer ao código de honra dos presos. É a relação dialética de distâncialproximidade com os códigos do universo carcerário que confere honra e permite aos crentes acessarem e transitarem entre os demais presos.

Ser considerado uma pessoa detentora de honra não ocorre por decreto e tampouco é perene. A honra é adquirida, entre os detentos crentes e nãocrentes, com o tempo, e em uma relação pessoal, onde a conduta é constantemente avaliada. 
A veracidade da conversão é observada com reservas e suspeição pelos detentos não-crentes. Mesmo os “irmãos” que já adquiriram o respeito dos demais presos têm seus atos sob constante vigilância. Essa desconfiança e o discurso de que os crentes freqüentam a igreja para receberem proteção de possíveis punições é mais proeminente quando o "irmão" já apresenta, ao ingressar no presídio, problemas de relacionamento com os detentos estupradores, ex-policiais, alcagüetes, dentre outros. Caso contrário, a dúvida acerca da sinceridade da conversão e as dificuldades para ser reconhecido como alguém detentor de honra, ainda que presentes, são atenuadas.

Os integrantes do Estrela do Cárcere, mesmo vivendo em uma galeria isolada dos demais presos, pregando o abandono completo da prática de crimes e sendo observados com desconfiança pelos demais detentos, estão distantes de serem outsiders dentro do universo carcerário. O grupo em questão representa uma força significativa e respeitada entre os detentos da PEJ. Isso se deve à organização e disciplina interna rígida - que utiliza, inclusive, puniçóes físicas em alguns casos de desrespeito às normas do grupo -, ao número de integrantes, ao status pessoal dos seus líderes no universo carcerário, ao respeito às leis dos presos e ao acesso que têm junto à direção do presídio e à comunidade civil.

No entanto, ainda que o Estrela do Cárcere seja considerado um grupo importante dentro do presídio, seus líderes, mesmo reconhecidos como homens honrados, são apenas interlocutores e não possuem nenhum tipo de ascendência hierárquica, participação ou ingerência nas decisões dos líderes das diversas facções criminosas que transcendam ao seu próprio grupo.

\section{REFERENNCIAS}

BOURDIEU, Pierre. O poder simbólico. 5. ed. Rio de Janeiro: Bertrand Brasil, 2002.

DUMONT, Louis. Homo hierarquicus: o sistema das castas e suas implicações. 2. ed. São Paulo: Edusp, 1997.

FOUCAULT, Michel. Vigiar e punir. 28. ed. Petrópolis: Vozes, 2004. 
GOFFMAN, Erving. Manicômios, prisóes e conventos. 7. ed. São Paulo: Perspectiva, 2003.

PERISTIANY, J. C. El concepto del honor en la sociedad mediterránea. Barcelona: Labor, 1968.

PITT-RIVERS, Julian. Honor y categoria social. In: PERISTIANY, J.C. El concepto del honor en la sociedad mediterránea. Barcelona: Labor, 1968. p. 21-76. 